\title{
Chemistry is pluralistic
}

\author{
Klaus Ruthenberg ${ }^{1}$ (D) Ave Mets $^{2}$
}

Published online: 7 July 2020

(c) The Author(s) 2020

\begin{abstract}
Recently, philosophers have come forth with approaches to chemistry based on its actual practice, imparting to it a proper aim and character of its own. These approaches add to the currently growing movement of pluralist philosophies of science. We draw on recent pluralist accounts from (the philosophy of) chemistry and analyse three notions from modern chemical practice and theory (acidity, electronegativity and the concept of element) in terms of these accounts, in order to complement the so far more general pluralist approaches with specific evidence. Our survey reveals that the concept of element indicates conceptual pluralisms in chemistry. that electronegativity illustrates methodological pluralism in determining one and the same concept, and that acidity is an instance of plurality hidden behind 'one notion'.
\end{abstract}

Keywords Pluralism $\cdot$ Plurality $\cdot$ Chemical elements $\cdot$ Acidity $\cdot$ Electronegativity

\section{Introduction}

For many years, chemistry has, explicitly or implicitly, been considered a branch of physics, which means that it has been treated as if it were part of the search for the ultimate building blocks and mathematical structures of nature. Yet in contrast to that view, chemistry is the science of substance changes, and one of its most central tasks is the making of stuff rather than the understanding of matter. Though theoretical descriptions can be very helpful in performing that task they are not as important in chemistry as they are in physics. In chemistry, empirical success comes first; the search for an ultimate and universal truth is hardly its intention. Chemical practices (e.g., the dialectical combination of synthesis and analysis, and the characterisation of substances) are generally different from those of physics. Though nobody would deny the usefulness of physical descriptions in chemistry, eliminative reductionism (the belief that every material behaviour is explainable

Klaus Ruthenberg

klaus.ruthenberg@hs-coburg.de

1 Faculty of Science, Coburg University of Applied Sciences and Arts, Coburg, Germany

2 University of Tartu, Institute of Philosophy, Tartu, Estonia 
in fundamental physical terms) is no longer a generally acceptable claim (see Primas 1981; Bunge 1982, and, particularly, van Brakel 2000). Rather it is one of several conceivable interdiscourse relations. ${ }^{1}$

Over the last 50 years or so, philosophy, and in particular philosophy of science, has undergone fundamental changes in thinking. Today, the interpretation of the target sciences no longer refers to abstracted, formal and mathematical description and explanation only. Theoretical physics no longer serves as the paradigm when it comes to representing 'real' sciences. Moreover, the One-World-One-Science Dogma (OWOS), which obviously entails a strong monistic claim, has been the target of severe attacks (Kukla 2010). It has thus become questionable whether it is justifiable to classify physics as the most fundamental science while downgrading all the other disciplines to 'specialised' sciences. The philosophies of other domains of the natural sciences have consistently received more and more attention, among which the philosophy of chemistry (in its modern form) has been one of the more recent departments (see, for example, the pertinent compilations Ruthenberg and van Brakel 2008; Woody et al. 2012; Schummer 2015; Scerri and Fisher 2016).

The greater emphasis on actual practice in the history of science has led to the recognition of the inherent pluralities of science. This in turn has given rise to pluralist views of scientific methodology and practices (e.g., Psarros 1999; van Brakel 2000; Chang 2004, 2012; Schummer 2015).

We seek to complement the more general investigations of scientific pluralism (see Dupré 1993; Kellert et al. 2006; Ruphy 2017) by introducing more specific aspects to the discussion and argue in favour of the claim set in the headline. We will begin this investigation with an overview of the theories of pluralism in philosophy of science, particularly in philosophy of chemistry ("Theories of pluralism and the philosophy of chemistry" section). To illustrate our point of view, we will then proceed to discuss three typical examples from modern chemistry which shall emphasise chemistry in practice rather than pure theoretical reasoning or speculation ("Case studies" section). "Conclusions" section presents our conclusions. We concede that the present contribution has the character of a preliminary survey and is kind of programmatic at the same time.

\section{Theories of pluralism and the philosophy of chemistry}

Scientific pluralism can have different meanings, several of which we will address in this section. To begin with, that is, as a working definition, we use the customary characterization that pluralism is the conviction that there is more than one way to success in science. Success in chemistry does not necessarily refer to theoretical issues. Rather, it refers to whether certain substantial situations can be realized (that is usually: whether a certain substance can be synthesized).

Ronald Giere aptly describes the general framework within which we may find most of these different approaches to pluralism:

\footnotetext{
1 Only in its extremer versions might reductionism be considered eliminative. A rare approach of a "moderate" reductionism from a chemo-philosophical point of view is Hettema (2012). See Bunge (1982) for an earlier criticism of the reductionist claims with respect to chemistry. We do not intend to go into further detail regarding that debate. Note, however, that our emphasis on pluralism necessarily opposes monism and the reductionism it entails.
} 
The one extreme is a (monistic) metaphysical realism according to which there is in principle one true and complete theory of everything. The other extreme is a constructivist relativism according to which scientific claims about any reality beyond that of ordinary experience are merely social conventions. (Giere 2006a, 26)

Giere himself $(2006 \mathrm{a}, \mathrm{b})$ proposes a perspectival pluralism based on the fact that sciences apply many different tools, including material apparatus, to study nature. Each of those has a specific interaction with reality and thus provides its own perspective on it. Instruments only interact with limited aspects of the world, and they 'process inputs from the environment in a way peculiar to their own physical makeup, ways that render these inputs similar or different not just according to features of the inputs themselves, but also according to features of the instrument.' (Giere 2006a, 59) Hence various understandings of one and the same object or phenomenon can exist and they can all be equally real. ${ }^{2}$

In addition to the extremes described by Giere, which seem to refer to ontological viewpoints ('metaphysical realism') on the one hand and epistemological approaches ('constructivist relativism') on the other, it can also be useful to differentiate two other forms of pluralism: the methodological and the theoretical form. ${ }^{3}$ Another way to differentiate pluralism seems to be that between theoretical and classificatory forms. We will return to that point later. At any rate we will follow the recommendation of Kellert et al. (2006) and separate plurality in from pluralism about chemistry.

Although Giere's approach is generally a useful one, we will place emphasis on those concepts that come from the philosophy of chemistry or are particularly likely to be applicable to chemistry.

\section{Jaap van Brakel}

One way to pluralism in the chemical sciences - though not explicitly denoted as pluralistic- - has been outlined by the Dutch philosopher Jaap van Brakel in his book Philosophy of Chemistry (van Brakel 2000). As a result of his investigation of reductionism, he concludes that usual hierarchical interdiscourse relations (e.g., reduction, emergence, superposition) do not in fact work (at least in the case of physics-chemistry). Rather, the different attempts to describe 'reality', like macroscopic, microscopic and submicroscopic approaches as well as non-specialist discourses, must be taken into account at the same time and without the customary assumption that only the most modern (microphysical) description is the 'real' and 'most scientific' one. If there is any asymmetry (if not hierarchy) at all in that system of knowledge, it lies in the priority of the manifest world in which any human inquiry originates (principle of empiricism).

\footnotetext{
${ }^{2}$ Note that the discussion of underdetermination in the general philosophy of science is in close relation to Giere's description.

3 We could also differentiate between descriptive and normative approaches. One early example of the latter can be found in Against Method (Feyerabend 1975). More recently, Hasok Chang has also advocated the benefits of scientific pluralism (Chang 2012).
} 
In this view, the description of water, to address the most prominent example, is as valuable in a quotidian sense as in its compositional or analytical depiction as $\mathrm{H}_{2} \mathrm{O} .{ }^{4}$

\section{Joachim Schummer}

The German philosopher Joachim Schummer has presented his criticism of form philosophy as opposed to stuff philosophy (Schummer 1996, 2008). One part of this criticism is his study of pluralism in chemistry. Science is fragmented into many disciplines and subdisciplines, which according to Schummer is in itself a strong argument for the claim that science as a whole is pluralistic (Schummer 2015). In chemistry, this fragmentation has led to an extreme specialisation, such that, for example, organic chemists from a certain segment of their discipline might not even be able to follow the work of their colleagues from another segment.

Schummer points at two reasons for the inevitability of the methodological pluralism in chemistry. First, the purposes within chemistry are manifold, and they are very different. As examples Schummer discusses stuff classification and the qualitative concepts this entails, the prediction/explanation of stuff behaviour and its necessarily quantitative concepts, and the operational concepts for synthetic purposes. Hence, a superior aim like 'scientific truth' cannot be encountered in chemistry. The second reason for the inevitable pluralism in chemistry refers to the epistemic limits of the latter. One central epistemic limit for chemistry is '.. the unbridgeable gap between the concepts and objects of chemistry'. (Schummer 2015, 62). In other words, substances are usually closer to reality than many abstracted (or theoretical) objects in other scientific domains:

... chemistry has addressed the realism/nominalism issue, which is sometimes misleadingly called the issue of natural kinds, by experimental means, largely unnoticed by mainstream philosophy. Rather than only adjusting our concepts by creating experimental systems to the world as it is, chemistry also adjusts the world to its concepts by creating experimental systems that best fit its frameworks (62).

Strangely enough, this point - the making of its own objects within chemistry by synthetic activities - is simply neglected in standard philosophy of science. Even the notion of construction in the philosophy of experiments customarily is applied to a static, unchanging world made up of stable building blocks, preferably elementary particles. The real 'chemical world', however, is fundamentally underdetermined, that is, the scientific description of a chemical substance does not stop at the level of a compositional formula. ${ }^{5}$ In order to decrease this ever-growing non-knowledge in chemistry, we need a plurality of methods.

\footnotetext{
4 Like van Brakel's 'intercultural' conclusion that there is 'no need for a metaphysical glue' between the different perspectives, the Argentinian philosopher of science Olimpia Lombardi and her group reject eliminative reductionism, be it motivated epistemologically or ontologically. Instead, they advocate what they call "ontological pluralism" (see Lombardi and Labarca 2005). According to these authors, a Kantian perspective allows us to give up the God's Eye viewpoint and to admit that different incompatible ontologies may coexist if grounded on pragmatically successful theories. From this point of view, chemistry is not only epistemologically, but also ontologically autonomous with respect to physics: the chemical world does not need to be referred to the physical domain to acquire ontological legitimacy.

5 Among the better-known examples referring to the issue of chemical underdetermination are dichlorodiphenyl-trichloroethane (DDT), the chlorofluorocarbons (CFC), thalidomide and carbon dioxide as well, but in principle every chemical individual is part of that phenomenon. In other words: The history of a substance is a never-ending story and full of surprises cf. Ruthenberg (2020).
} 


\section{Hasok Chang}

Another more recent approach with a strong and explicit pluralist emphasis and reference to the substantial realm is advocated by the Korean-American historian and philosopher of science Hasok Chang. In his books Inventing Temperature (Chang 2004) and Is Water $\mathrm{H}_{2} \mathrm{O}$ ? (Chang 2012), Chang develops what he calls the complementary science view with respect to the main task or function of history and philosophy of science. Seen from that perspective, history and philosophy of science takes up very similar questions as science itself, but these questions may have been excluded by the latter because it has since specialised on other topics. According to Chang, science itself and its interpretation can and should be other than constricted and monistic: there is no general need to judge between the different pictures of the world.

Chang's pluralism is related to his division of scientific practice into three levels: operations, activities and systems (Chang 2012, 15-17). According to this division, a system of scientific practice ${ }^{6}$ consists of epistemic activities. An epistemic activity is a 'more-or-less coherent set of mental or physical operations that are intended to contribute to the production or improvement of knowledge in a particular way, in accordance of some discernible rules.' Coherence of an activity is determined by its success in achieving its aim. Epistemic activities normally are both mental and material: applying scientific apparatus is material but understanding it as scientific apparatus and understanding what it does is mental; and conversely, mental aspects of science such as models and theories require material input. Various epistemic activities are practised in relation to each other, not in isolation. A coherent, goal-orientated set of epistemic activities forms a system of practice. Although activities may be divided into ever 'lower' levels of constituent activities, down to operations, this does not mean that we arrive at something elementary and simple in the end. Rather, each operation itself presumes further operations to make it coherent (like measurement presumes calibration, etc.).

Chang's pluralism lies in the acknowledgement that different systems of practice address different problem fields (note that this corresponds to Schummer's first criterion for a methodological pluralism in chemistry). They are not merely tested against evidence, but the evidence to test against is chosen (Chang 2012, 19-20) according to their different aims and questions. For instance, aside from common interests, the phlogistonist and oxygenist systems also had diverging research questions that the other 'competing' system could not address (20-21). This is one of the causes that justifies the existence of both theories in parallel. Another cause is that different systems of practice hold different epistemic values, hence they compose different accounts of common research objects. Comparing the phlogistonist and oxygenist systems from this aspect, Chang brings forth the following epistemic values: simplicity or elegance vs completeness (22-23); conservatism vs reform or novelty (25); pluralism vs absolutism (25-26). Also the different systems may hold the same values but interpret them in divergent ways, e.g. in the case of the value of unity, what exactly is unified, which phenomena?; for systematic regularity, what should be approached systematically (e.g. assigning like cause to like effects, handling new phenomena); for empiricism, which things are deemed as empirically grounded? (27-29).

Any analysis of case studies will therefore have to consider the different aims of the competing theories or systems of knowledge, how they perform in reaching those aims:

\footnotetext{
${ }^{6}$ Chang prefers the term 'system of scientific practice' instead of Kuhn's 'paradigm', which is close to it, for its more concrete and compact meaning in comparison to the latter.
} 
What the actions and operations are and whether they are coherent and successful, and how their epistemic values help them reach those aims.

\section{Rein Vihalemm}

The Estonian philosopher of chemistry Rein Vihalemm differentiates the sciences into $\varphi$-sciences (exact sciences), non- $\varphi$-sciences (natural sciences) and social-humanities studies. This distinction stems directly from his first specialisation-chemistry. He criticises (physicalist) monism as to chemistry (Vihalemm 2011). ${ }^{7}$ In his view, chemistry has a dual nature: it is both $\varphi$ - and non- $\varphi$-scientific: 'Chemistry as non- $\varphi$-science aims to identify and classify substances and their modes of transformation, whereas chemistry as $\varphi$-science investigates what in the substances, what in their properties and transformations, can be modelled as obeying laws of nature' (Vihalemm 2016a). Hence, he can be considered a pluralist, or a minimalist proponent of pluralism with respect to methodologies and aims of chemistry. ${ }^{8}$ Concerning concrete practical activities in chemistry, however, Vihalemm remains rather implicit, not exemplifying his approach much.

\section{Case studies}

We refer here to the following three cases: chemical elements, acidity and electronegativity. All these topics address core conceptions of the science of substance changes in practice, and all include both classificatory and theoretical aspects. Historical aspects are not emphasized in this section.

\section{Chemical elements}

Chemical substances, whether elements or compounds, can be characterized and classified in many different ways. According to the philosophical extremes of these approaches, we can differentiate two poles, the phenomenological and the microstructuralist approaches. ${ }^{9}$ This coexistence of a diversity of stuff descriptions already hints at a general plurality or pluralism in chemistry. The question emerges as to whether we should call this fact theoretical or classificatory.

Modern chemical elements are 'officially' defined by the assumption that they are 'made of' atoms that have the same number of protons, that is, the same atomic number, in their nuclei. These atomic numbers are used as one criterion in the Periodic Table. In real

\footnotetext{
7 Note that in Vihalemm (2011) the author considers Wilhelm Ostwald to be a monist. Although Ostwald himself explicitly claimed to be a follower of (energetic) monism, it is important to recognize that an ontological monism (like Ostwald's) can go with an epistemological pluralism. In his practical work as analytical and physical chemist, Ostwald used a variety of partly phenomenological methods to characterize substance behaviour like affinity. Hence, he was an ontological monist and an epistemological pluralist at the same time.

${ }^{8}$ He does not, however, agree with Chang's normative pluralism as expounded in Chang (2012). In his criticism of Chang, Vihalemm also seems to lay more emphasis on $\varphi$-science aspects than a convinced pluralist would allow for Vihalemm (2016b).

9 Several of these approaches are presented in Ruthenberg and van Brakel (2008). Proponents of the poles mentioned include Soentgen (2008) and Hendry (2008).
} 
life, however, for example in laboratories, experts obviously work with (sometimes very small) portions of observable stuff samples rather than with atoms, not to mention atomic nuclei. ${ }^{10}$ Only with highly specialized and sophisticated instrumentation borrowed from or developed together with their colleagues from physics and technology might chemists be able to measure atomic numbers. The second criterion for the construction of the Periodic Table, however, is not as 'easily' inferred from measurement as atomic numbers, because it is derived from chemical experience. The invention of the verticals (the groups) in the Periodic Table is a chemical achievement with its roots in the early nineteenth century. What in practice was compared here were certain compounds of what became elements and their behaviour. Sometimes, even substances that had not yet been purified were baptized as chemical elements. Hence, the Periodic Table has been developed by application of a vast and diverse store of knowledge obtained from stuff manipulations.

There is another issue here. Lavoisier's definition of elements as those substances which cannot be broken down into other 'simple' substances still seems to be in good order. In fact, as we have hinted to above, the characterisation or identification of chemical elements is usually performed without in-depth studies of their composition. The standard case is that chemists collect specific pieces of information like melting point, boiling point, triple point, spectra, reaction (synthetic) behaviour, to determine the nature of an element. Hence, the 'correction' from atomic weights to atomic numbers in the early twentieth century was doubtlessly crucial for the improvement of the Periodic Table, but less important for the practical definition of chemical elements. In a certain sense, even chemical elements are the result of stuff preparations rather than of the discovery of collections of a bunch of atoms of the same atomic number. ${ }^{11}$

Consider the notorious example of gold. How has this material made its way to become an element? We know about this material from historical descriptions. Gilding techniques, for example, have been known since antiquity, and even the technique of dissolving the metal by the application of aqua regia was developed long before the eighteenth century, probably in the Arab world in early medieval times. The knowledge about the characterisation and classification of gold, for example the analysis of its quality with respect to its use as 'noble' metal, is several hundred years old, and had already been a tradition long before Lavoisier's modern definition of elements and even longer before modern atomic physics. Obviously, Aristotle (like Plato) did not consider this metal to be an element in the prevailing four-element concept of his time, but that does not mean that he had no clue about it as a chemical individual. The methods for classification of chemical kinds have certainly improved over time. The individuality of these kinds, however, has stayed the same since a certain point in time, and no single property—not even the atomic number-can be said to have determined the most reliable description.

Chemical elements are at centre stage in the debates about natural kinds. In a critical discussion of pluralism in chemistry, Robin Hendry states:

\footnotetext{
10 This simple fact from real science does not hinder both experts and laymen to refer to substances as if they are made of submicroscopic particles. This abstract reference to composition is not wrong only in a quite trivial sense. Actual chemical science is nevertheless not like that, which is the very point.

11 This very issue, a kind of intensification of the principle of Berthelot (chemistry is making its own objects) was advocated by the Bohemian chemist Frantisek Wald. He compared the preparation of elemental samples with the dissection or making of skeletons or mummies (Wald 1902).
} 
Pluralism about natural kinds is the thesis that there is more than one way to classify things, and that, from a purely ontological point of view, none of these ways is privileged over the others. (Hendry 2012, 61).

Hendry claims that there is one privileged approach among the many mentioned. In contrast to van Brakel's view, for example, he believes that the microphysical descriptions provide more reliable knowledge about substances and their classification than the purely empirical observations.

In modern chemistry, both the 'chemical' definition according to Lavoisier and the 'physical' definition by atomic numbers do indeed coexist. As a young pioneer of radiochemistry, Friedrich Paneth (1887-1958) published the article 'Über den Element- und Atombegriff in Chemie und Radiologie', in which he differentiates the two variations of element definition as 'practical' and 'theoretical' (Paneth 1916). Later, namely in his 'Königsberg lecture', he applied an interpretation of Kant's dualist epistemology and called the manifest (empirical) elemental substances 'simple' entities and those defined by atomic numbers 'basic' entities (Paneth 1931) (Fig. 1).

Many non-pluralists (monists, essentialists, reductionists, physicalists, materialists, and strict realists) emphasize the structural or physical path of classification and underestimate the empirical part of the investigation and its systematic background. In other words, they believe that the atomic number is the actual and only fixed designator of chemical elements and they usually do not care about its empirical background in their theory-centred discussions. On the face of it, Paneth would seem to be such a scholar, an impression which in fact led to the 'official' modern element definition by the IUPAC around 1920. This impression, however, is at least partially misleading. It is misleading because Paneth, from 1916 on, consistently argued against the careless colonization of chemistry by physics. We feel his true point of view is well characterised in a paper he presented in 1934 titled "Chemische Elemente und Urmaterie: Mendeleevs Ansicht und der heutige Standpunkt" (Paneth 1964), in which he quotes Gaston Bachelard ${ }^{12}$ as stating that the thinking of chemists 'oscillates between the pluralism of one part and the reduction of the plurality of the other part'. Obviously, the French historian and philosopher of science observed a dualism similar to that of Paneth. ${ }^{13}$ The latter comments:

Rather than calling it oscillation, it seems to me that it would be better to speak of simultaneous development in different branches. The reduction to unity (or quadruplicity ${ }^{14}$ ) has been successfully achieved by physics; chemistry, however, will probably preserve, as long as there is a science of chemistry in the present meaning of the word, a plurality of its basic substances (...) (Paneth 1964, 70)

That statement corresponds to his dualistic theory, a fact we interpret as the simplest version of pluralism, at least in an epistemological sense.

\footnotetext{
12 Bachelard (1932) published his book Le Pluralisme cohérent de la Chimie moderne.

13 Note the similarity of the dualism discussed here to Vihalemm's epistemic-methodological description of chemistry.

14 The contemporary elementary particle physics differentiated four items: the proton, two electrons $( \pm)$, and the neutrino.
} 
Hence, chemical elements are in fact characterisable or classifiable by different means, whether typically chemical or not. ${ }^{15}$ If we were to search for a hierarchy or priority list of these different ways of characterisation (which Hendry, for example, seems to have in mind) we would have to emphasize the empirical nature of any approach. Even the determination of atomic numbers is an empirical act, although not typically chemical, which could well be subsumed under what Paneth called the 'practical' or 'empirical' mode. ${ }^{16}$ There is no need for a metaphysical glue, as van Brakel has put it, and there also seems to be no need for a strict and demarcating dualist picture either. ${ }^{17}$ Nevertheless, the latter is useful for discussing the interrelations between characterisation and classification methods for chemical elements and for evaluating their relevance. As the primary result of such discussion we obtain a broad diversity rather than one central essence. Moreover, though conceivable in general, the distinction of classificatory and theoretical forms of pluralism is not easy to perform when it comes to the description of substances.

Taking these methods to be material and embedded in the corresponding scientific practices in which they arise, let us continue the analysis in terms of the practical and empiricist accounts provided in the previous chapter.

In Chang's (2012) terms, the two notions of elements arise from different scientific practices motivated by and hence answering different problems and questions. Even though both concern identification of concrete elements, the notion of element as simple substance concerns macroscopic chemical properties of elements, whereas a definition of element based on atomic numbers concerns a microphysical property. The first is embedded in the analysis-synthesis practices of chemical laboratories, the second in the measurement in sophisticated physical apparatus, e.g. X-ray tubes.

Historically, however, the two are clearly related and hence indicate the import of Chang's urge to plurality of scientific practices with the emphasis on their interaction (Chang 2012). Particularly the determination of the elemental mass proportions was crucial in analysis-synthesis practices, as something that persists through chemical changes, unlike most other properties, including chemical ones. That determination concerned atomic weights (initially equivalent weights) that came to be deemed as unique and hence as defining and identifying elements (which underlies the structure of the Periodic Table).

In Vihalemm's terms, on the one hand, we should consider both the chemical and the physical definitions of elements as necessary and having their aim; particularly, as his understanding of chemistry includes the physical or exact scientific aspect, the atomic number would belong to the $\varphi$-scientific core of chemistry, not be excluded from it. Would this mean that the atomic number is the unique numerical property of elements is their primary determinant? Vihalemm does consider chemistry's natural scientific aspect,

\footnotetext{
15 If we want to measure atomic numbers, for example, we need to gain knowledge about the quality and purity of the applied portion of substance, that is knowledge about how to prepare the sample, and we need to know how to calibrate the measuring process. Both are only possible using qualitative information.

16 Note that modern transactinide 'chemistry' is not chemistry at all in that the production of super heavy elements (SHE) leads to very small numbers of atomic nuclei rather than to stuff samples. The making of SHE may yield (new) elements, but by no means elemental substances. In Paneth's words, there are only "basic' substances here, but no 'simple' ones.

17 Paneth wishes to use the word 'transcendental' for 'beyond direct observability'. Though this is a fascinating topic, we do not intend to enter the debate about observability, the 'demarcation debate', here. There are two poles of that debate: the declaration of everything measurable as 'observable' on the one hand, and the idea of separating unaided observation from instrumentalized experience on the other hand. Complicated transitional states between those poles are possible, see electronegativity.
} 


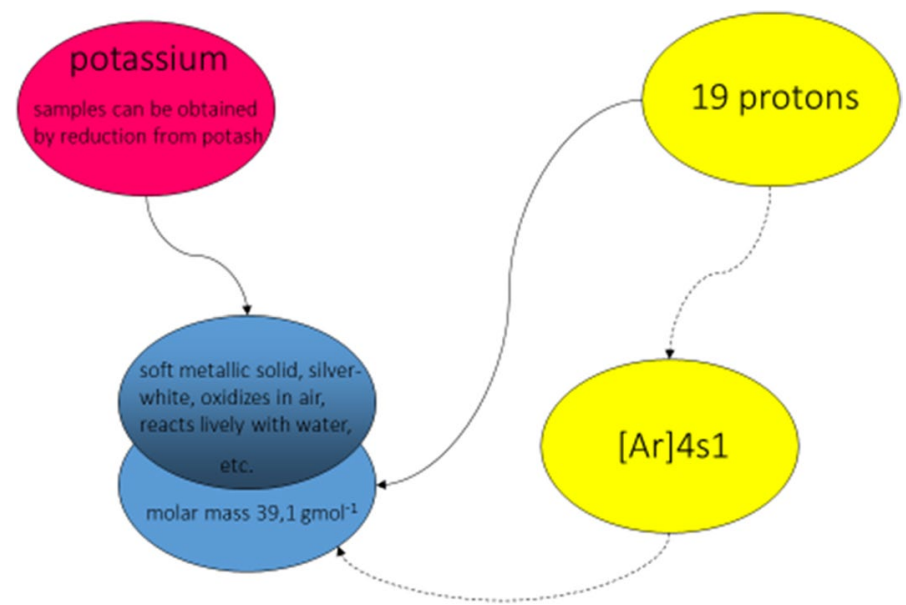

Fig. 1 Schematic picture of the dualist approach to chemical elements (with potassium as an example) according to Friedrich Paneth in his 'Königsberg lecture' (Paneth 1931). The two balloons on the lower left represent the 'simple' (chemical, empirical) descriptions of elements and the 'basic' (physical, theoretical) ones. The atomic number has a direct connection to the 'basic' version, whereas the path via the atomistic theory (here as the electronic configuration) is not a necessary one according to Paneth and therefore dotted

exploring chemical properties of substances, as essential to the field. On the other hand, as Vihalemm denounces diverging definitions of fundamental terms, should one of them be rejected instead? Those two definitions do not exclude each other nor compete with one another in practice like the varying definitions of phlogiston did. Also, neither is reducible to the other in theory, since the phenomenological properties of elements are in general not deducible from the atomic numbers ${ }^{18}$ Hence the different definitions should be in no contradiction with each other and the two aspects would be on equal footing.

According to Giere's perspectival pluralism, we may state that the different aspects of elements that physical and chemical methods capture are both real. Whether the mechanism is the various substances and their analyses-syntheses, or x-ray tubes, they interact in their own ways with simple substances to create different realities. Once those realities and the ways to create them have become epistemically certain, each can have their theories or models built on their base, for example the theories of atomic structure (consisting of protons, electrons and neutrons, and their relation to atomic weight).

Concluding this section, we feel justified in claiming that in the representation of chemical substances theoretical and classificatory aspects of scientific work are not easily differentiated. The pluralism with respect to stuff is peculiar to chemistry but is neither purely theoretical nor purely descriptive. ${ }^{19}$

\footnotetext{
18 Vihalemm rejects, however, the notion of "chemical force" as a force of a separate kind because of the more fundamental microphysical realm.

19 This claim corresponds to what Schummer called the 'unbridgeable gap between the concepts and objects of chemistry'. It also corresponds to the general dialectic between analysis and synthesis in chemistry.
} 


\section{Acidity}

Consider the following narrative: An average second-year student of chemistry is confronted with the following statement: 'The hard acid $\mathrm{H}^{+}$and the hard base $\mathrm{OH}^{-}$react faster and yield stronger bonds than soft acids would do with hard bases and hard acids with soft bases.' Already introduced to the 'classical' Brönsted/Lowry theory in the first-year course of general chemistry, ${ }^{20}$ the student might wonder why those two well-known ions are called hard now, and is taught the HSAB concept which was introduced by Pearson in the 1960s: Hard acids and hard bases are those chemical species which are small, highly oxidated, electronegative (bases), and hard to polarize. Our student might even understand that this really complex, abstract and unquantifiable model has been invented to better describe the reactivity of chemical substances in general, not only that of the classical acids and bases. But she might have her problems with the fact that those groups of species go by the same assignments as the former proton-donors or proton-acceptors, that is by the name of acidity.

Is there any relationship between those different theoretical approaches? And, by the way, she might as well wonder about reactions like $\mathrm{H}^{+}+\mathrm{H}^{-} \rightarrow \mathrm{H}_{2}$ : Is that not a really fast (if not the fastest) chemical reaction, and the product an extraordinarily stable substance, although the hydride ion was presented as the paradigm example of a soft base? And what about the ions which lead to the mysterious ' 7 ' in the $\mathrm{pH}$ value of pure water: why are these stable?

Our student remembers a similar situation, namely when the acidity theory of Lewiswhich is the basis of Pearson's approach—was introduced, another one for qualitative purposes which is very useful in explaining reaction mechanisms, particularly in organic chemistry. She never fully understood, however, why the product of an acid/base neutralisation according to Brönsted/Lowry, namely water, can become a Lewis base, when it, for example, functions as hydrating molecule in a dissolved metal ion complex. Obviously, the protonists and the electronists use the same word, but they mean different things. ${ }^{21}$

As to the protonists, the puzzled student would admit that she always liked the stuffrelated (or compositional) early concept, which had its precursor with Liebig (exchangeability of metals against hydrogen), and, particularly, Arrhenius (hydrogen ions as bearers of acidity) in the nineteenth century. It is very plausible to her that it is a stuff that is responsible for acidity: If her orange juice is diluted by mineral water, it tastes less sour. However, the $\mathrm{pH}$ concept (the negative decadic logarithm of the molar concentration of the hydrogen cations in aqueous solutions) does not sound entirely plausible to her. She was raised intellectually with pocket calculators and computers, so the transformation of a measurable concentration into a seemingly simple and nondimensional number appears troublesome to her, as it has to many generations of her fellow students (especially in exams).

The $\mathrm{pH}$ concept would probably not be invented again in our times because all these measured numbers can be represented and processed easily by modern calculators.

\footnotetext{
${ }^{20}$ In 1923, Brönsted and Lowry independently described acids as substances which enhance the hydrogen ion concentration (proton-donors) and bases as substances which diminish the hydrogen ion concentration (proton-acceptors; in water, the most important proton-acceptor is the $\mathrm{OH}^{-}$ion) This substance-related theory has its predecessor with Arrhenius' theory of electrolytic dissociation (1887). In 1909, S. Sørensen introduced the $\mathrm{pH}$ algorithm, which transfers the molar hydrogen concentration into a logarithmic number.

21 For a study of the quotidian background of acidity see Ruthenberg and Chang (2017). Stanford and Kitcher (2000) discuss acidity referring to the causal theory of reference.
} 
Although the logarithmic description is not necessary in terms of scientific law, the $\mathrm{pH}$ is a widely applied concept in practical chemistry.

As outlined in the narrative above, there are two theoretical lines in modern acidity, which we might call 'electronism' and 'protonism'. The former, introduced by Gilbert Lewis, emphasizes mechanistically the role of the outer electrons, the latter, in the tradition of Arrhenius and Brønsted/Lowry, depicts a substantial entity, the hydrogen ions, as the cause of acidity. Do both approaches speak of the same phenomenon? Obviously not.

In his Representing and Intervening, Ian Hacking briefly addresses just this question (Hacking 1983, 84-85). In his critique of Putnam's theory of meaning, he briefly describes both theoretical approaches and discusses the problem of referring the central notions of these approaches to certain phenomena or substances, which is the inevitable problem of reference. It becomes clear that the electronist and the protonist cannot both claim the same natural kind status for what they respectively call 'acid' or 'base'. At least, and this is our interpretation, the protonist is closer to the notion of substance, which is more important than any other theoretical expression in chemistry. Moreover, until today there has been no way to quantify or measure Lewis acids and bases (as acids and bases, not just as concentration determinations like for other arbitrary substances). In contrast, the protonists have the $\mathrm{pH}$ as measurement method (which, as indicated above, has its own difficulties). Hacking does not answer the question here what to label as a natural kind, nor does he go into much detail, but he brushes off Putnam's approach:

This example reminds us that the notion of meaning is ill-adapted to philosophy of science. We should worry about kinds of acids, not kinds of meaning. (Hacking $1983,85)$

Hacking uses the well-chosen expression 'bifurcating kinds' for the departure of the electronists from the protonists around 1923. Intriguingly, both concepts are still in use, and nobody seems really to care about the conceptual difficulties our chemistry students may run into when the established experts use the word 'acid' in different meanings, experimental settings and explanatory applications without further ado.

What kind of pluralism do we have here? Or is it only a kind of contingent plurality ${ }^{22}$ ? As early as 1923, Gilbert Lewis made it perfectly clear that he was what in modern philosophy of science would be called a realist with respect to theories:

... a basic substance is one which has a lone pair of electrons which may be used to complete the stable group of another atom, and that an acid substance is one which can employ a lone pair from another molecule in completing the stable group of one of it atoms. (Lewis 1923, 142)

The quotidian basis of the protonist approach no longer plays any significant role in this extreme generalization. According to Lewis, the hydrogen cations $\left(\mathrm{H}^{+}\right)$, for example, are acidic (as any other cation) and the hydrogen anions $\left(\mathrm{H}^{-}\right)$basic (as any other anion). In this utterly structuralist way of theoretical description the peculiarities of acidity, if not the contact to substance reality, are weakened. The coexistence of these two different applications of the notion 'acidity' is not just a contingent plurality. There is a vantage point of the bifurcation, initiated by Lewis in order to advocate modern chemical theory, because

\footnotetext{
22 Plurality is "a feature of the present state of inquiry". Pluralism is "a view about this state of affairs [for instance] that plurality in science possibly represents an ineliminable character of scientific inquiry and knowledge" (Kellert et al. 2006, ix).
} 
to him protonism was a kind of old-fashioned dogma. At that vantage point pluralism was present, but soon the situation became a kind of plurality. The protonists did not really care, presumably because the Lewis concept did not really imperil their own conception, particularly in practice, which just at that time had begun to become very successful and gain widespread acceptance. Consequently, nobody complained about the novel use of the well-introduced notion 'acidity'. The result is the coexistence of those two concepts we still have today, one deeply rooted in quotidian experience and in principle measurable, the other one theoretically extremely abstract, and both addressing largely different topics. ${ }^{23}$ Nevertheless, there is some similarity to the case of the chemical elements. As we have seen, the empirical classification of elements comprises very different methods, some of which are close to wet chemistry work, whereas others are quite remote from the customary chemical laboratory. What Paneth depicted as 'basic' elementary substance, defined by atomic number, finds a kind of equivalent in Lewis' electronism. The talk about electrons is a talk about (chemical) unobservables, ${ }^{24}$ as is the talk about atomic numbers in chemistry, too.

\section{Electronegativity}

According to the prevailing meaning of observability in physics, electronegativity is not observable, that is there is no 'direct' path to measure it. It is a quantified concept, but at the same time not precisely defined (Ruthenberg and Martinez Gonzalez 2017). Nevertheless, it is a paradigm case when it comes to the discussion of chemical reactivity, particularly the nature of chemical bonds and the polarity in chemical compounds. Electronegativity can be initially characterised as the ability or potential of chemical species (elements, atoms, molecules) to attract bonding electrons (cf. Pauling 1932, Atkins and de Paula 2013). There are several empirical domains from which data can be obtained to derive quantified electronegativities from, among which are thermochemistry, spectroscopy and dipole moments (Pritchard and Skinner 1955).

The result of such calculations are scales of small relational numbers (the highest of which is usually set to 4 for fluorine). Every modern element chart includes these numbers. The capability of atomic entities to attract electrons is a highly abstracted instance. It can be described by a multitude of methods, but direct measurement is not possible. Electronegativity is relational. There is no absolute single value for elements. The deviations between those scales are very small, so that it seems that most of these approaches converge, that is they refer to the same property. This leads some authors to the tempting conclusion that electronegativity is a natural property or natural kind (Leach 2013). However, we do not intend to enter the natural kind debate here.

Electronegativity can indeed serve as a prime example for Schummer's description of the methodological pluralism in chemistry as well as a very good example for van Brakel's non-hierarchical, intercultural approach. As for substances, there is a kind of unifying basic chemical intuition with respect to the behaviour of substances here as well. This central chemical concept is as successful in terms of qualitative explanation as it is inconceivable theoretically.

\footnotetext{
${ }^{23}$ Chang comes to a similar conclusion. He compares the 'bifurcation' of acidity following Lewis with the naturalised naming of the concept of oxidation without connection to the element oxygen (Chang 2016, 42).

${ }^{24}$ Hacking's 'if we can spray them, they are real' is not applicable here. In everyday chemical work, electrons are theoretical entities.
} 
Due to the lack of a precise definition, one could surmise that this notion does not fit into Vihalemm's exact or natural sciences and is instead congruent with social sciences. However, the various instrumental determinations of electronegativity are congruent with exact sciences, for the scales obtained are characteristic of precise measurement. Hence this notion seems to have an unexpected kind of dual (or even triple?) character in Vihalemm's conception.

As to Giere's perspectivism, the various methods for measuring electronegativity are due to the varying phenomena that substances as material objects, and electronegativity as a 'theoretical' concept, participate in. These include thermochemical and spectroscopic phenomena, and they provide results that can be interpreted in identical terms of electronegativity partly due to their convergence. This resembles Giere's example of colour vision in that as a certain colour perception can be arrived at by different real world configurations, so a certain value of electronegativity can be arrived at by different real world experimental configurations, implying a plurality of experiment models too. But contrary to a coloured object that appears differently in different conditions, the same substance yields converging results in different configurations measuring electronegativity. Hence there is a plurality of experimental models, but convergence of representational models here. Nonetheless, pluralism of real phenomena due to methodological pluralism, encompassing the same aspect of the material world (electronegativity) is a legitimate concept here.

In Chang's terms the various physical and chemical methods of studying the concept (or intuitive property) of electronegativity are instances of different scientific systems of practice, consisting of different activities and operations, and addressing different problem fields and questions. Hence, their results are different. The thermochemical approach according to Pauling, for example, could not obtain any information about the noble gases, because these lack compounds to work on. According to Mulliken, however, electronegativities of the noble gases can be described (Ruthenberg and Martinez Gonzalez 2017). Again, the question arises as to which of these applications we wish to consider the more 'chemical', and perhaps we will find out that they are complementary in a certain sense.

\section{Conclusions}

Scientific pluralism, the view that there is more than one way to success in methodology and theory, is inevitable in chemistry. The examples we have examined from the theory and practice of modern chemistry - the concept of element, acidity and electronegativityhave illuminated different kinds of pluralism to be found in chemistry, in a range from plurality (or "weak pluralism") to pluralism proper (or "strong pluralism"). The different concepts of element, one physical and the other chemical, show that the non-exact-scientific or non-mathematical (non-numeric) description is viable and necessary in chemical laboratory practice, whereas the atomic number-based definition/identification is restricted to theoretical discourses. Hence a conceptual pluralism should be adopted that would do justice to chemists' actual work, which is not adequately described in purely structural terms. Electronegativity underscores the methodological-experimental pluralism in use in both chemical practices and their underlying theories. The same intuitively perceived property has multifarious interactions with other phenomena studied by different subfields or systems of practice, providing multiple ways to empirically enact and measure it. Acidity in turn seems to be a hybrid example, where a single term is applied to very different concepts-different with respect to their practical import. Historically, the starting point 
of electronism and protonism saw a conceptual overlap, but the theoretical terms used in either account of acidity yield not only differing systems of practice, but also differing outcomes.

These examples and their analysis in terms of pluralist philosophies of science provide further evidence to the need for and topicality of a pluralist understanding of science. Firstly, chemistry as a highly diverging discipline is inherently pluralist methodologically, theoretically and conceptually and cannot be subsumed under one unified essence of chemical science. Secondly, it certainly cannot be reduced to physics as a more fundamental science, that is to its basic entities, theories and methods. Chemistry is a very practical science in that it makes its own epistemic entities, and this practice must be accounted for on its own terms. Such account, which is our main conclusion, must entail pluralistic ideas.

The present contribution is the first explicit and concrete survey of pluralism in chemistry, which also can be considered as a positive reaction to reductionistic claims. It contributes to the question about the peculiarities of chemistry rather than to struggle with the "problem" why chemistry is not physics. The ideas of a few historical authors as well as some modern philosophers of chemistry which we discussed here offer some support in favour of pluralism. The conceptual area of these ideas covers a wide range. Whether we subscribe to Bachelard and his statement of a theoretical oscillation between reductionism and pluralism or to Paneth's (or Vihalemm's) dualism of coexisting approaches, whether we think of the supremacy of substance-making (Schummer) or a hierarchy of explanatory concepts in chemistry (Hendry), whether we advocate intercultural equality (van Brakel) or emphasize the benefits of scientific pluralism and make it a research programme (Chang), one point should have become clear by this survey: chemistry is pluralistic.

Acknowledgements Open Access funding provided by Projekt DEAL. Two anonymous reviewers for the Foundations gave helpful suggestions which we gratefully appreciate. We also thank Endla Löhkivi (Tartu) and Apostolos Gerontas (Coburg) for their support during the joint research project on pluralism in chemistry. The research for this article was supported by the BAYINTAN, Bavaria, the Estonian Research Council grants PRG462 and IUT20-5, University of Tartu grant PHVFI16941, and the European Union through the European Regional Development Fund (Centre of Excellence in Estonian Studies).

Open Access This article is licensed under a Creative Commons Attribution 4.0 International License, which permits use, sharing, adaptation, distribution and reproduction in any medium or format, as long as you give appropriate credit to the original author(s) and the source, provide a link to the Creative Commons licence, and indicate if changes were made. The images or other third party material in this article are included in the article's Creative Commons licence, unless indicated otherwise in a credit line to the material. If material is not included in the article's Creative Commons licence and your intended use is not permitted by statutory regulation or exceeds the permitted use, you will need to obtain permission directly from the copyright holder. To view a copy of this licence, visit http://creativecommons.org/licenses/by/4.0/.

\section{References}

Atkins, P., de Paula, J.: Elements of Physical Chemistry, 6th edn. Oxford University Press, Oxford (2013)

Bachelard, G.: Le Pluralisme Cohérent de la Chimie Moderne. Vrin, Paris (1932)

Bunge, M.: Is chemistry a branch of physics? Z. Allg. Wiss. 13(2), 209-223 (1982)

Chang, H.: Inventing Temperature. Oxford University Press, Oxford (2004)

Chang, H.: Is Water H2O? Evidence, Pluralism and Realism. Boston Studies in the Philosophy of Science. Springer, Dordrecht (2012)

Chang, H.: The rising of chemical natural kinds through epistemic iteration. In: Kendig, C. (ed.) Natural

Kinds and Classification in Scientific Practice. Routledge, London (2016)

Dupré, J.: The Disorder of Things. Harvard University Press, Cambridge (1993)

Feyerabend, P.: Against Method. Verso Editions, London (1975) 
Giere, R.: Scientific Perspectivism. University of Chicago Press, Chicago and London (2006a)

Giere, R.: Perspectival pluralism. In: Kellert, S.H., et al. (eds.) Scientific Pluralism, pp. 26-41. University of Minnesota Press, Minneapolis (2006b)

Hacking, I.: Representing and Intervening. Cambridge University Press, Cambridge (1983)

Hendry, R.: Microstructuralism: problems and prospects. In: Ruthenberg, K., van Brakel, J. (eds.) Stuff, pp. 107-121. Königshausen \& Neumann, Würzburg (2008)

Hendry, R.: Chemical substances and the limits of pluralism. Found. Chem. 14, 55-68 (2012)

Hettema, H.: Reducing Chemistry to Physics. Rijksuniversiteit, Groningen (2012)

Kellert, S.H., Longino, H.E., Waters, C.K. (eds.): Scientific Pluralism. Minnesota Studies in the Philosophy of Science, vol. 19. University of Minnesota Press, Minneapolis (2006)

Kukla, A.: Extraterrestrials-A Philosophical Perspective. Lexington Books, Lanham (2010)

Leach, M.R.: Concerning electronegativity as a basic elemental property and why the periodic table is usually represented in its medium form. Found. Chem. 15, 13-29 (2013)

Lewis, G.N.: Valence and the Structure of Atoms and Molecules. The Chemical Catalog Company, New York (1923)

Lombardi, O., Labarca, M.: The ontological autonomy of the chemical world. Found. Chem. 7, 125-148 (2005)

Paneth, F.A.: Über den element- und atombegriff in chemie und radiologie. Z. Phys. Chem. 91, 171-198 (1916)

Paneth, F.A.: Über die erkenntnistheoretische Stellung des chemischen Elementbegriffs (1931). Schriften der Königsberger Gelehrten Gesellschaft 8 (Heft 4), 101-125 (1931). (The citation and pagination refers to the English translation. Br. J. Philo. Sci. 13, 1-14, 144-160) (1962)

Paneth, F.A.: Chemical elements and primordial matter: Mendeleeff's view and the present position. In: Dingle, H., Martin, G.R. (eds.) Chemistry and Beyond, pp. 53-72. Interscience Publishers, New York (1964)

Pauling, L.: The nature of the chemical bond. IV. The energy of single bonds and the relative electronegativity of atoms. J. Am. Chem. Soc. 54, 3570-3582 (1932)

Primas, H.: Chemistry, Quantum Mechanics and Reductionism. Springer, Heidelberg (1981)

Pritchard, H.O., Skinner, H.A.: The concept of electronegativity. Chem. Rev. 55, 745-786 (1955)

Psarros, N.: Die Chemie und ihre Methoden. Wiley, Weinheim (1999)

Ruphy, S.: Scientific Pluralism Reconsidered: A New Approach to the (Dis)unity of Science. University of Pittsburgh Press, Pittsburgh (2017)

Ruthenberg, K.: »Caught in the Amber«: A sketch of chemical underdetermination. In: LaCaze, A., Osimani, B. (eds.) Uncertainty in Pharmacology, pp. 173-184. Springer, Cham (2020)

Ruthenberg, K., Chang, H.: Acidity: Modes of characterization and quantification. Stud. Hist. Philos. Sci. 65-66, 121-131 (2017)

Ruthenberg, K., Martinez Gonzalez, J.C.: Electronegativity and its multiple faces: persistence and measurement. Found. Chem. 19, 61-75 (2017)

Ruthenberg, K., van Brakel, J. (eds.): Stuff-The Nature of Chemical Substances. Königshausen \& Neumann, Würzburg (2008)

Scerri, E., Fisher, G.: Essays in the Philosophy of Chemistry. Oxford University Press, Oxford (2016)

Schummer, J.: Realismus und Chemie. Königshausen \& Neumann, Würzburg (1996)

Schummer, J.: Matter versus form, and beyond. In: Ruthenberg, K., van Brakel, J. (eds.) Stuff, pp. 3-18. Würzburg, Königshausen \& Neumann (2008)

Schummer, J.: The methodological pluralism of chemistry and its philosophical implications. In: Scerri, E., McIntyre, L. (eds.) Philosophy of Chemistry-Growth of a New Discipline. Springer, Dordrecht (2015)

Soentgen, J.: Stuff: a phenomenological definition. In: Ruthenberg, K., van Brakel, J. (eds.) Stuff, pp. 71-91. Würzburg, Königshausen \& Neumann (2008)

Stanford, P.K., Kitcher, P.: Refining the causal theory of reference for natural kind terms. Philos. Stud. 97, 99-129 (2000)

van Brakel, J.: Philosophy of Chemistry. Leuven University Press, Leuven (2000)

Vihalemm, R.: A monistic or pluralistic view of science: Why bother? Abh. Sächsischen Akad. Wiss. Leipzig 82(Heft 1), 79-93 (2011)

Vihalemm, R.: Science, $\varphi$-science, and the dual character of chemistry. In: Scerri, E.R., Fisher, G.A. (eds.) Essays, pp. 352-379. Oxford University Press, Oxford (2016a) 
Vihalemm, R.: Chemistry and the problem of pluralism in science: an analysis concerning philosophical and scientific disagreements. Found. Chem. 18, 91-102 (2016b)

Wald, F.: Kritische Studie über die wichtigsten chemischen Grundbegriffe. Ann. Naturphilos. 1(15-19), 182-216 (1902)

Woody, A., Hendry, R., Needham, P. (eds.): Handbook of the Philosophy of Science-Philosophy of Chemistry. Elsevier, Amsterdam (2012)

Publisher's Note Springer Nature remains neutral with regard to jurisdictional claims in published maps and institutional affiliations. 